\title{
Identification of a GTP-bound Rho specific scFv molecular sensor by phage display selection Marine Goffinet ${ }^{1,2,3}$, Patrick Chinestra1,2,3, Isabelle Lajoie-Mazenc 1,2,3, Claire Medale-Giamarchi1,2,3, Gilles Favre*1,2,3 and Jean-Charles Faye*1,2,3
}

\author{
Address: 1NSERM U563, CPTP, "Signalisation cellulaire, GTPase Rho et cancers", F-31052, Toulouse, France, ${ }^{2}$ Institut Claudius Regaud \\ Département de Biologie, F-31052, Toulouse, France and '3Université Paul Sabatier, Faculté des Sciences Pharmaceutiques, F-31062, Toulouse, \\ France \\ Email: Marine Goffinet - goffinet.marine@claudiusregaud.fr; Patrick Chinestra - chinestra.patrick@claudiusregaud.fr; Isabelle Lajoie- \\ Mazenc - lajoie.isabelle@claudiusregaud.fr; Claire Medale-Giamarchi - medale.claire@claudiusregaud.fr; \\ Gilles Favre* - favre.gilles@claudiusregaud.fr; Jean-Charles Faye* - faye.jean-charles@claudiusregaud.fr \\ * Corresponding authors
}

Published: 3I March 2008

BMC Biotechnology 2008, 8:34 doi:10.1 I86/1472-6750-8-34
Received: 13 July 2007

Accepted: 31 March 2008

This article is available from: http://www.biomedcentral.com/1472-6750/8/34

(C) 2008 Goffinet et al; licensee BioMed Central Ltd.

This is an Open Access article distributed under the terms of the Creative Commons Attribution License (http://creativecommons.org/licenses/by/2.0), which permits unrestricted use, distribution, and reproduction in any medium, provided the original work is properly cited.

\begin{abstract}
Background: The Rho GTPases A, B and C proteins, members of the Rho family whose activity is regulated by GDP/GTP cycling, function in many cellular pathways controlling proliferation and have recently been implicated in tumorigenesis. Although overexpression of Rho GTPases has been correlated with tumorigenesis, only their GTP-bound forms are able to activate the signalling pathways implicated in tumorigenesis. Thus, the focus of much recent research has been to identify biological tools capable of quantifying the level of cellular GTP-bound Rho, or determining the subcellular location of activation. However useful, these tools used to study the mechanism of Rho activation still have limitations. The aim of the present work was to employ phage display to identify a conformationally-specific single chain fragment variable $(\mathrm{scFv})$ that recognizes the active, GTPbound, form of Rho GTPases and is able to discriminate it from the inactive, GDP-bound, Rho in endogenous settings.
\end{abstract}

Results: After five rounds of phage selection using a constitutively activated mutant of RhoB (RhoBQ63L), three scFvs (A8, Cl and DII) were selected for subsequent analysis. Further biochemical characterization was pursued for the single clone, $\mathrm{Cl}$, exhibiting an scFv structure. $\mathrm{Cl}$ was selective for the GTP-bound form of RhoA, RhoB, as well as RhoC, and failed to recognize GTP-loaded Racl or Cdc42, two other members of the Rho family. To enhance its production, soluble $\mathrm{Cl}$ was expressed in fusion with the $\mathrm{N}$-terminal domain of phage protein plll (scFv $\mathrm{Cl}$ NIN2), it appeared specifically associated with GTP-loaded recombinant RhoA and RhoB via immunoprecipitation, and endogenous activated Rho in HeLa cells as determined by immunofluorescence.

Conclusion: We identified an antibody, CI-NIN2, specific for the GTP-bound form of RhoB from a phage library, and confirmed its specificity towards GTP-bound RhoA and RhoC, as well as RhoB. The success of $\mathrm{CI}-\mathrm{NIN} 2$ in discriminating activated Rho in immunofluorescence studies implies that this new tool, in collaboration with currently used RhoA and B antibodies, has the potential to analyze Rho activation in cell function and tumor development. 


\section{Background}

The Rho GTPases proteins are members of a large superfamily of regulatory proteins whose activities are controlled by regulated GDP/GTP cycling. To date, a total of 22 Rho family members have been suggested by the data available from the human genome sequence project. The Rho GTPases can be divided into six groups: Rho (RhoA, RhoB, RhoC), Rac (Rac1, Rac2, Rac3, RhoG), Cdc42 (Cdc42, TC10, TCL, Chp/Wrch-2, Wrch-1), Rnd (Rnd1, Rnd2, Rnd3/RhoE), RhoBTB (RhoBTB1 and RhoBTB2) and Miro (Miro-1 and Miro-2). Additional members, RhoD, Rif and TTF/RhoH, do not fall into any of these subfamilies [1].

Rho GTPases control a wide variety of signal transduction pathways regulating many fundamental processes of cell biology, such as organization of the actin cytoskeleton [2], gene expression, cell proliferation and survival [3]. Most Rho proteins cycle between an active GTP-bound state and an inactive GDP-bound state. Binding to GTP is promoted by Rho guanine nucleotide exchange factors (RhoGEFs), and GTP hydrolysis is catalysed by Rho GTPaseactivating proteins (Rho-GAPs). Rho-GDP dissociation inhibitors (Rho-GDIs) stabilize the GDP-bound form of Rho proteins.

Rho proteins are also implicated in participating in several steps of tumor progression and development of metastasis $[4,5]$. Activated Rho proteins cooperate strongly with oncogenes Ras and Raf in focus-formation assays, but either fail to independently induce transformation or else exhibit weak transforming activity [6-9]. They function in cell cycle regulation by the modulation of cyclin D1 [10] and by their involvement in endocytic traffic $[11,12]$, such as in regulation of epidermal growth factor receptor [13]. Furthermore, Lacal et al have shown that Rho GTPases are directly involved in signalling pathways that trigger either proliferation or cell death [14]. Moreover, expression of activated Rac protects against Ras-induced apoptosis [15].

These studies linking Rho proteins to many aspects of cellular proliferation are further extended by the study by Gomez del Pulgar, which revealed that several human tumors contained aberrant expression and activation of Rho GTPases [16]. Elevated expression of RhoA and RhoC was found in breast, lung, ovarian, gastric, and bladder cancers. The involvement of RhoA in testicular human tumors was demonstrated by increased RhoA mRNA levels in relation to tumour grade [17]. Overexpression of the rhoC gene in adenocarcinoma of pancreas correlated with poorer prognosis of patients [18], whereas RhoB expression is lost in several tumors [19]. Moreover, unlike Ras, no mutated, constitutively active forms of Rho proteins in tumors have thus far been identified [20], apart from one report linking hyperactive Rac3 with highly proliferative human breast cancer cells and tumor tissues [21]. Whatever the level of gene expressions of Rho GTPases and assuming that high level of protein could be associate with higher concentration of activated Rho GTPase, the knowledge of accurate variations of the Rho activation under treatment would be a significant progress in the understanding of the biological role of Rho in oncogenesis.

To further develop understanding of Rho activation, we identified a conformation-specific scFv against the active form of RhoA, RhoB and RhoC GTPases. We employed a phage display approach, which has previously demonstrated successful results in generating precise sensors of variations in molecular conformation [22]. To this end, we utilized the Q63L mutant [23] of RhoB (locked in the GTP binding structure), and expressed this mutant as a GST fusion protein in E. coli and used the purified recombinant protein as a target ligand for selection of recombinant scFv. Using the Griffin.1 library [24], one clone (C1) was selected for its ability to discriminate between the activated versus the unactivated form of RhoB, as well as RhoA and RhoC, but not other Rho family members. The selected $\mathrm{C} 1 \mathrm{scFv}$ was fused to a fragment of phage coat protein pIII gene to enhance its production, expressed in E. coli, and its specificity confirmed. Finally, its ability to detect endogenous activated Rho in vivo in immunofluorescence studies is shown.

\section{Results and Discussion}

\section{Identification of RhoBQ63L specific interacting phages}

Peptide and protein libraries on filamentous phages, in combination with effective selection strategies, have proven to be a rapid and successful method to identify proteins with specific binding properties. A major advantage of the in vitro selection process by phage display is the extensive control of the selection conditions, which, for example, allowed the preservation of the three-dimensional structure of GTP-bound form of Rho. Using the Griffin.1 phage display library, Perez et al identified scFvs that act as molecular conformation sensors by showing selectivity towards the GTP-bound conformation of the Rab6 GTPase [22]. The present work used the same phagemid library containing more than $10^{9}$ independent clones. Each clone expresses human recombinant antibodies as a single-chain $\mathrm{Fv}(\mathrm{scFv})$, where both $m y c$, $6 x \mathrm{His}$ tags, and the pIII protein of M13 are fused to the C-terminus of immunoglobulin $\mathrm{V}_{\mathrm{H}}-\mathrm{V}_{\mathrm{L}}$ fusion (Fig 1).

Due to its ability to decrease the kinetics of GTP hydrolysis, RhoBQ63L is considered as a "GTP-locked" mutant of RhoB. We expressed and purified the GST-tagged RhoBQ63L mutant in Escherichia coli, and used the recombinant protein as target for phage selection. For the first round of selection, we collected phage bound to GST- 


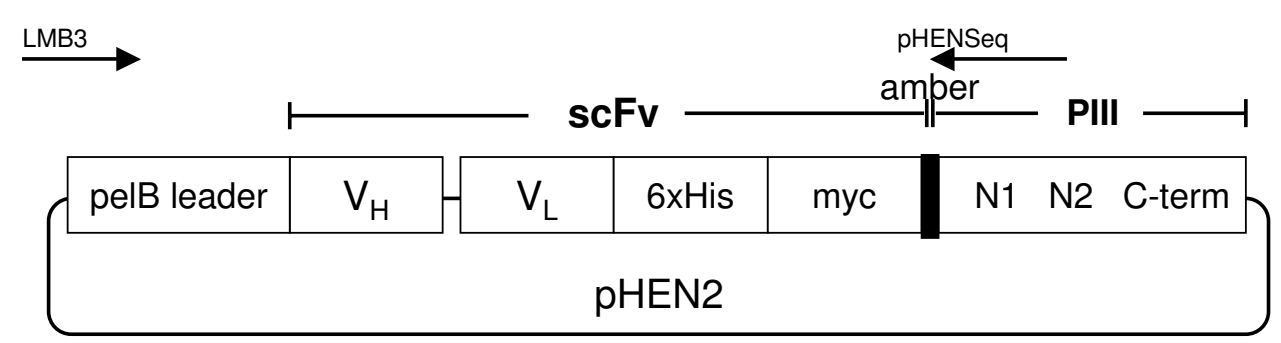

B

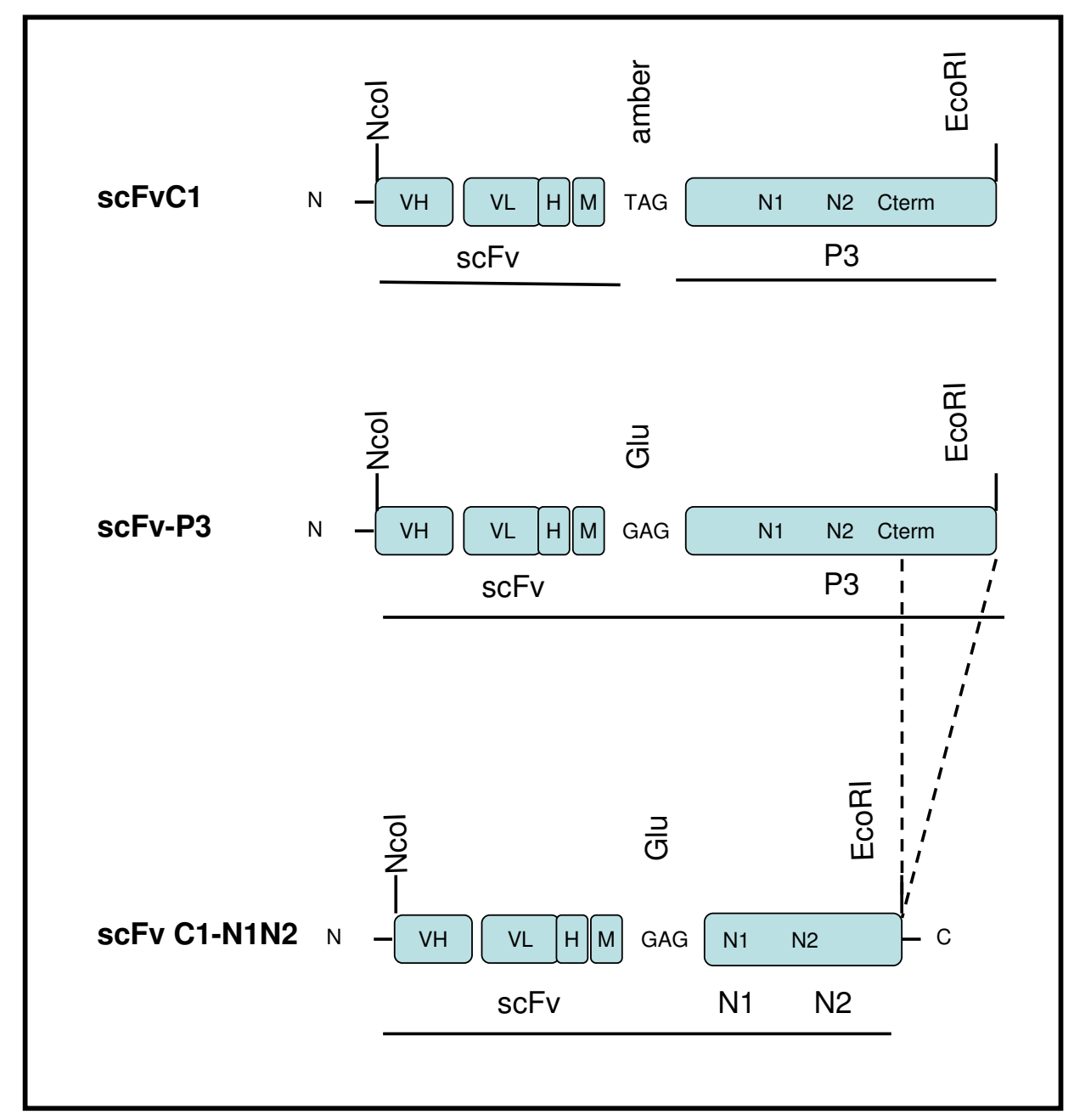

Figure I

pHEN2 vector and construction of scFv CI-NIN2. A: Schematic representation of the pHEN2 phagemid vector (Griffin I. library). pelB leader: signal peptide sequence of bacterial pectate lyase that mediates secretion into the periplasmic space; $V_{H}$ : variable fragment of the heavy chain; $V_{\mathrm{L}}$ : light chain; $6 x$ His: 6 histidine-tag; myc: myc-tag; amber: amber stop codon; NI, N2, Cterm: portions of the $\mathrm{N}$ - and $\mathrm{C}$-term of phage capside protein plll; LMB3 and pHENSeq: primers used for sequencing the $\mathrm{V}_{H}$ and $V_{L}$ domain. B: Schematic construction of vectors encoding soluble scFv $\mathrm{Cl}$ and scFv CI-NIN2. The amber stop codon between the scFv and gene III in pHEN 2 was removed by mutagenesis (middle construct). The C-terminal portion of plll was removed in the final pHEN CI-NIN2 vector (bottom construct), first by PCR amplification of pHEN CI-plll, introducing an EcoRI site after N2, and subsequently by cloning the $\mathrm{Ncol}$ and EcoRI digested PCR product into the linearized pHEN Cl-plll plasmid at the Notl and EcoRI sites. H: 6 histidine-tag; M: myc-tag. 
RhoBQ63L-bound beads. For the subsequent four rounds, selection was a two-part process: we first preblocked phage on GST-beads, and the phage mixture was then loaded on GST-RhoBQ63L beads. During the last round, soluble recombinant wild-type RhoB was added into the phage mixture to specifically select phage that interact only with the active GST-RhoBQ63L form on the beads. Rounds IV and V contained polyclonal phage specific to GST-RhoBQ63L. To increase isolation of positive clones, we initiated two independent screenings from round V: V-1 and V-2. In total, 144 (48 from the V-1 and 96 from the $\mathrm{V}-2$ ) clones were randomly picked and checked by ELISA, yielding 8 RhoBQ63L selective phages.

\section{Characterization of the selected single chain antibodies}

To characterize the 8 RhoBQ63L selective phages, their specificity was first examined by analyzing their interaction with GST, GST-RhoB and GST-RhoBQ63L (Fig 2A). Six of the phages showed preferential binding to the GTPlocked RhoBQ63L mutant, while two clones (E2 and E12) failed to interact and were discarded (Fig 2A).

To assess the specificity of the selected $\mathrm{scFv}$ against the GTP-bound form of the three Rho proteins of interest, C1 and control phages were tested by ELISA with the wild type form of RhoA, B and C (WT) and their corresponding active forms (Q63L). As shown in Fig 2B, C1 phage showed significant reactivity against the Q63L mutant of all three Rho proteins. In contrast, the reactivity against the WT form was very low in most cases, and within the range of the background response. As predicted, the $\mathrm{C} 1$ phage does not discriminate between the GTP-bound form of RhoA, B, C, suggesting that $\mathrm{C} 1$ is directed against the GTP binding domain or against the effector-binding domain shared at almost 100\% identity among the three proteins. This also suggests that the carboxy terminal hyper-variable domain of these proteins, which functions to target membrane localization, has little importance in the conformation of the active form.

DNA sequencing of the 6 preselected clones revealed three unique scFv sequences for phages C1, D11 and A8 (Fig 3), although scFv D11 and A8 only contained sequence for the variable heavy chain, $\mathrm{V}_{\mathrm{H}}$. The major differences between the amino-acid sequences of the three clones were concentrated in the hypervariable complementarydetermining regions, CDR2 and CDR3, of the $\mathrm{V}_{\mathrm{H}}$. The $\mathrm{A} 8$ and D11 phages proved to be unstable. They quickly lost their recognition properties, and were discarded. Thus, only the $\mathrm{C} 1$ phage was kept for further analysis.

\section{Biochemical characterization of the specific binding of scFv Cl}

In order to further determine whether $\mathrm{C} 1$ specifically detected Rho proteins in their GTP-bound conformation, we next assayed $\mathrm{C} 1$ binding to Rho protein preloaded with GTP. First, GST-RhoA expressed and purified onto glutathione beads was loaded with GDP or the slowly hydrolyzable analogue of GTP, GTP $\gamma$, to ensure maximum loading of RhoA with the nucleotide [25]. C1 phage was next added and incubated for 1 hour, and bound C1 phages were measured with anti-M13. As seen in Fig 4A, the $\mathrm{C} 1$ binding increased up to $75 \mathrm{~min}$ after loading with GTP $\gamma$ S until a steady state was reached. Under similar incubation conditions, in the presence of GDP, the C1 phage recognition of RhoA did not change. To further confirm the Rho GTP-bound conformational specificity of $\mathrm{C} 1$, nucleotide-binding assays with RhoB and RhoC were tested in comparison with RhoA. C1 phages bound specifically to GTP $\gamma \mathrm{S}$ but not GDP preloaded RhoA, RhoB and RhoC (Fig 4B).

Interestingly, when we tested the binding of $\mathrm{C} 1$ phage against the GTP-bound form of Rac1 and Cdc42, two wellcharacterized members of two separate subfamilies of Rho GTPases, C1 phages bound selectively on GTP $\gamma \mathrm{S}-\mathrm{RhoB}$ but not GTP $\gamma$ S-Rac1 or GTP $\gamma$ S-Cdc42 (Fig 4C), despite their ability to successfully bind GTP (insert Fig 4C). Together this demonstrated that the scFv C1-pIII fusion protein specifically targeted the GTP-bound form of RhoA, RhoB and RhoC, and was unable to recognize GTP $\gamma \mathrm{S}$ or GDP preloaded Rac1 and Cdc42, two other Rho subfamily members.

\section{Expression and activity analysis of recombinant scFvCl}

To further characterize scFv C1 binding, we constructed and expressed recombinant $\mathrm{scFv} \mathrm{C} 1$ protein. The pHEN2 phagemid vector carries an amber codon (TAG) at the Cterminal of the scFv sequence and prior to the M13 pIII sequence (Fig 1B, top panel). Non-suppressive strains, such as BL21, interpret the amber codon as a translation stop signal, thus the $\mathrm{scFv} \mathrm{C} 1$ is expressed in soluble form and can be purified via the histidine tags. Crude bacterial extract from cells expressing $\mathrm{scFv} \mathrm{C} 1$, as confirmed by Western Blot analysis with anti-c-myc antibodies, lost its ability to bind RhoAQ63L (Fig 5A). The multiple supplementary bands observed in the blot would be explained by the renowned propensity of scFv to form dimeric and higher-order aggregates. This loss of function is a common observation when phage-display derived scFvs are expressed as soluble scFvs. Jensen $e t$ al. reported that an inactive antibody fragment can be functionally rescued by fusion to the N-terminal domain of the original phage display fusion partner, filamentous phage protein III [26]. We employed a similar approach and mutated the amber codon to allow translation and fusion to the $\mathrm{N}$ terminal of pIII, as well as removed the C terminal of pIII (Fig 1B, scFv C1-N1N2, bottom panel). As shown in Fig 5B, scFv C1$\mathrm{N} 1 \mathrm{~N} 2$ exhibited the predicted molecular mass of $60 \mathrm{kDa}$. Furthermore, the bacterial lysate expressing $\mathrm{scFv} \mathrm{C} 1$ - 


\section{A}

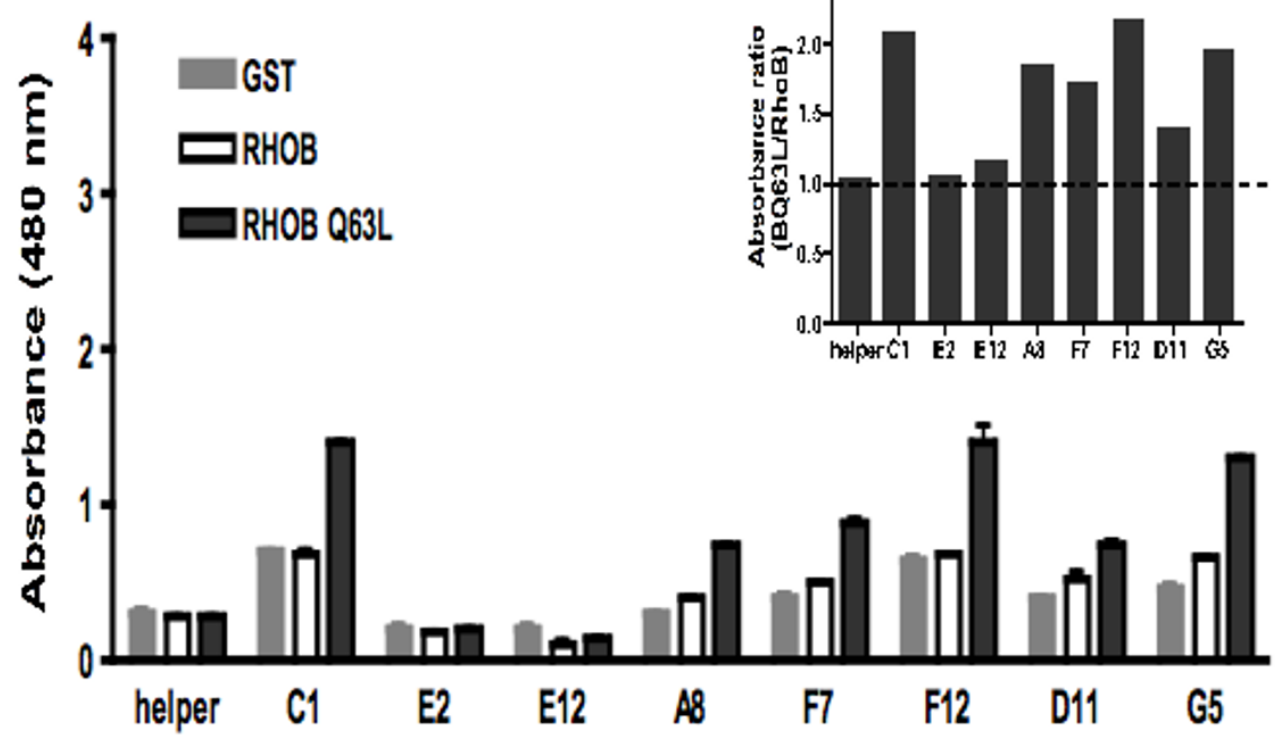

B

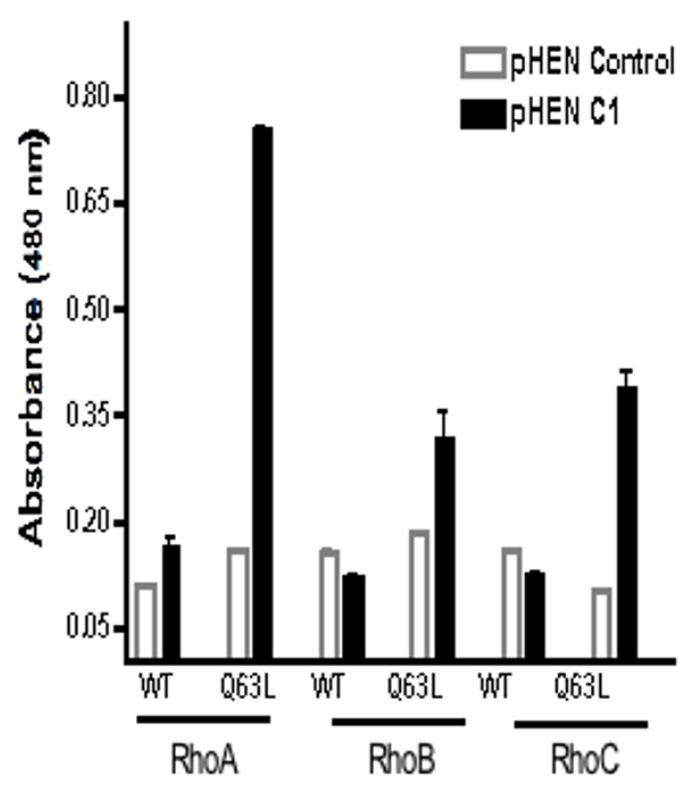

Figure 2

Phage binding specificity towards RhoQ63L compared to wild-type Rho. A: Ten monoclonal phages from E. coli supernatant were analyzed for binding to GST (grey columns), GST-RhoB (white columns) and GST-RhoBQ63L (black columns) protein immobilized on an ELISA plate. Bound phages were detected with horseradish peroxydase-labeled anti-MI 3 using TMB as substrate. Helper phage was used as a control. Results are expressed as absorbance at $480 \mathrm{~nm}$. Insert: ratio of absorbance of binding to RhoBQ63L to absorbance of binding to RhoB. B: Selectivity of CI phages on WT and activated Q63L form of Rho. $10^{10}$ clones of $\mathrm{Cl}$ (black columns) and control (white columns) phage were analyzed for binding to GST-RhoA, RhoB and RhoC, both wild type (WT) and Q63L forms, immobilized on a glutathione ELISA plate. Bound phages were detected with horseradish peroxydase-labeled anti-MI3 using TMB as substrate. Results are expressed as absorbance at 480 $\mathrm{nm}$. Concentrations of GST-Rho proteins in each well were monitored by anti-GST (not shown). The graph is representative for 3 experiments, and each binding assay was performed in duplicate. 


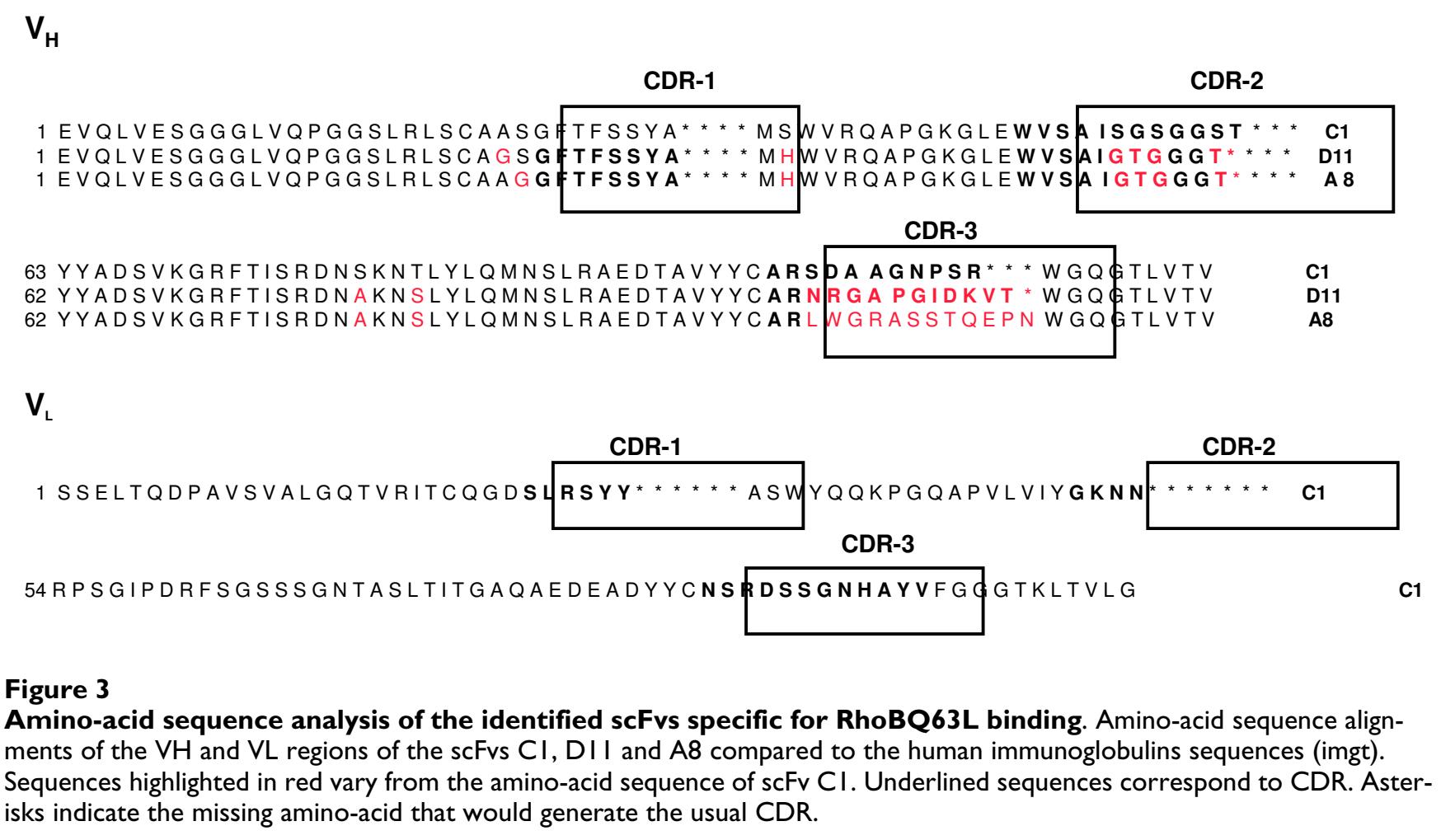

N1N2 was now able to selectively recognize RhoAQ63L versus RhoA as determined by ELISA. Competitive experiments between scFvC1-N1N2 and the Rho binding domain of Rhotekin (RBD) have been analyzed and are summarized in Table 1 . RBD alone is not stable enough to be used in this study, however the chimere GST-RBD is able to compete with scFvC1-N1N2 on RhoAQ63L and shows an affinity more than 10 fold higher than the $\mathrm{scFv}$ C1-N1N2. Affinities for GDP-Rho, GTP-Cdc42 and GTPRac1 are too weak to be determined.

The new recombinant $\mathrm{C} 1-\mathrm{N} 1 \mathrm{~N} 2$ fusion protein was expressed more easily in a soluble form, and showed higher binding to RhoAQ63L. We then purified scFv C1N1N2 from crude extract by incubation with Ni-NTA agarose beads and elution with imidazole, and aliquots from each step were analyzed by SDS PAGE (Fig 6A). The binding activity towards RhoAQ63L of scFv C1-N1N2 crude extract and the four elutions fractions were tested and confirmed by ELISA (Fig 6B). As seen on the SDS PAGE various proteins with lower molecular mass than scFvC1$\mathrm{N} 1 \mathrm{~N} 2$ are co-purified with the desired probe. As reported by others these proteins would be the result of translational arrest in the N1N2 sequence of the phage PIII.

To measure the affinity of this $\mathrm{scFv}$, surface plasmon resonance (SPR) experiments were performed on a Biacore 3000 instrument [27]. Using the previously described methodology by Horn et al, we bound GST-RhoA loaded with GDP on one flowcell (FC1), and GST-RhoA loaded with GTP $\gamma$ S on a second flowcell (FC2) [28]. C1-N1N2 "antibody" was injected at a concentration of 2.5 and 8 $\mu \mathrm{M}$ using a flow rate of $20 \mu \mathrm{l} / \mathrm{min}$. In order to test the specificity of $\mathrm{scFv} \mathrm{C} 1-\mathrm{N} 1 \mathrm{~N} 2$ for the GTP-bound form of RhoA, differential responses (FC2-FC1) were recorded and analyzed using the Biaevaluation 4.0 software (Biacore $\mathrm{AB}$ ). The results supported the GTP-bound conformational specificity, with an apparent dissociation constant $\left(K_{D}\right)$ in the range of $3 \pm 1 \mu \mathrm{M}$ (data not shown). Similarly, affinity of a scFv molecule for GTP-bound Ras was previously reported in the range of $1.3 \mu \mathrm{M}$ [29]. Same results were found with GST-Cdc 42 and GST-Rac 1 loaded with GTP $\gamma$ S are coated on FC1 in front of GSTRhoA loaded with GTP $\gamma$ S on FC2.

\section{Recombinant scFv CI-NIN2 used as sensor of GTP-bound Rho in vitro and in vivo}

We determined the ability of the antibody to immunoprecipitate RhoA and RhoB in their GTP-bound conformations. Crude bacterial extracts expressing scFv C1-N1N2 was incubated with Ni-NTA beads to immobilize the antibody, and bacterial lysate containing recombinant RhoA or RhoB preloaded with GDP or GTP were mixed with these beads. RhoA and RhoB specifically bound to the scFv C1-N1N2 beads were analysed by Western Blot with commercial anti-RhoA and anti-RhoB antibodies (Fig 


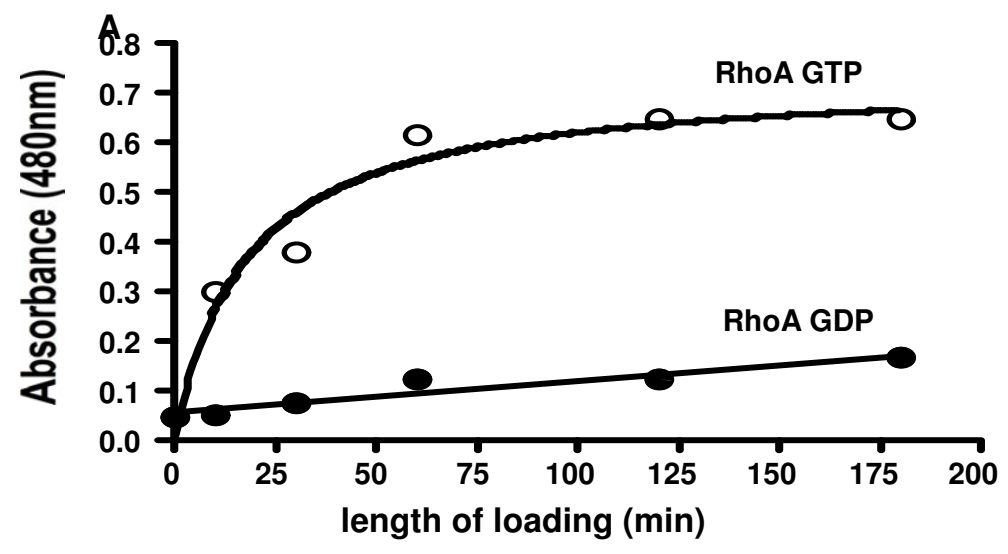

B

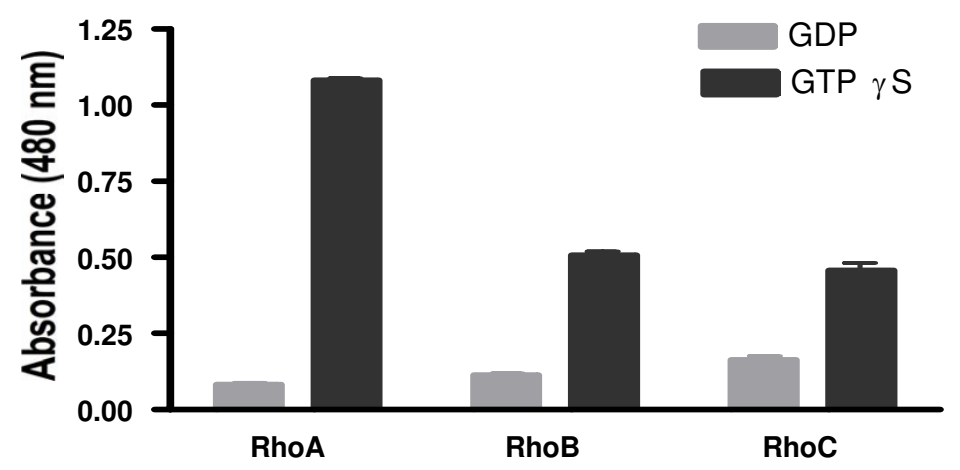

C

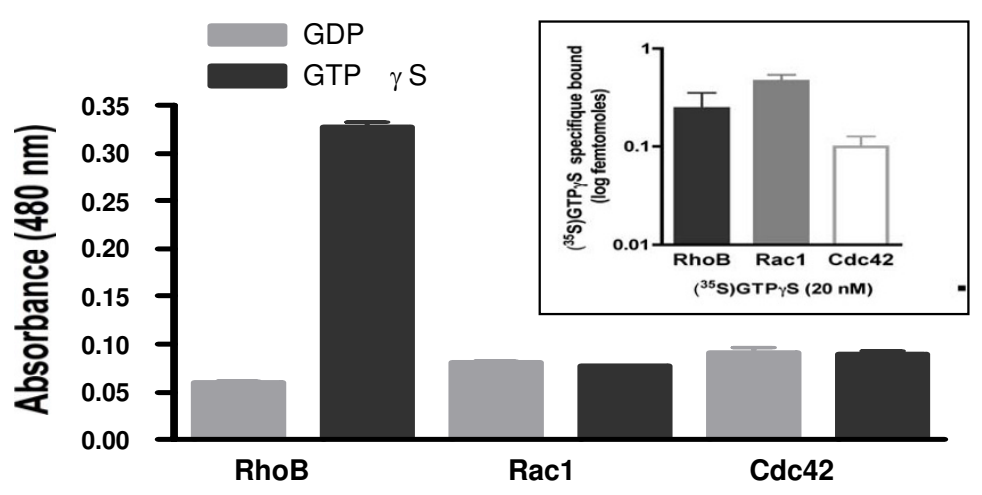

Figure 4

Specificity of CI phage binding to GTP-bound Rho family members. A: Kinetics of GTP loading on RhoA. GST-RhoA immobilized on gluthatione beads was loaded with $100 \mu \mathrm{M}$ of GDP and $\mathrm{GTP} \gamma \mathrm{S}$ at $37^{\circ} \mathrm{C}$. $10^{1}$ 'clones of $\mathrm{Cl}$ phages were incubated with loaded (GTP or GDP) GST-RhoA-bound beads. Bound phages were detected with horseradish peroxydase-labeled anti-MI3 using TMB as substrate. Results are expressed as absorbance at $480 \mathrm{~nm}$. The graph is representative of 2 independents experiments. GST-RhoA, B and C (B) and GST-RhoB, Racl and Cdc42 (C) were loaded with $200 \mu M$ of GDP or GTP $\gamma$ S for $30 \mathrm{~min}$ and purified on glutathione ELISA plates. $10^{10}$ clones of $\mathrm{Cl}$ phages were incubated in each well. Bound phages were detected with horseradish peroxydase-labeled anti-MI3 using TMB as substrate. Results are expressed as absorbance at 480 $\mathrm{nm}$. Amount of GST protein was quantified with goat anti-GST antibody followed by horseradish peroxydase-labeled anti-goat (not shown). The graph is representative of 3 experiments, each binding assay performed in duplicate. Insert: Specific radioactivity binding of [ $\left.{ }^{35} \mathrm{~S}\right] \mathrm{GTP} \gamma \mathrm{S}$ on RhoB, Racl and Cdc42. GST-RhoB, Racl and Cdc42 were loaded with $20 \mathrm{nM}$ [ ${ }^{35} \mathrm{~S}$ ] GTP $\gamma \mathrm{S}$ in the presence (non specific binding) or not (total binding) of $200 \mu \mathrm{M}$ unlabeled GTP for 30 minutes at $37^{\circ} \mathrm{C}$ and purified on gluthatione ELISA plates. Radioactivity was measured in each well. The difference between the total binding and the non specific binding represent the specific binding. The graph is representative of 2 experiments, each performed in triplicate. 
A

$$
\text { scFvC1 } \quad \mathrm{N}-\mathrm{VH} \text { VL } \mathrm{HM} T \mathrm{TAG}
$$
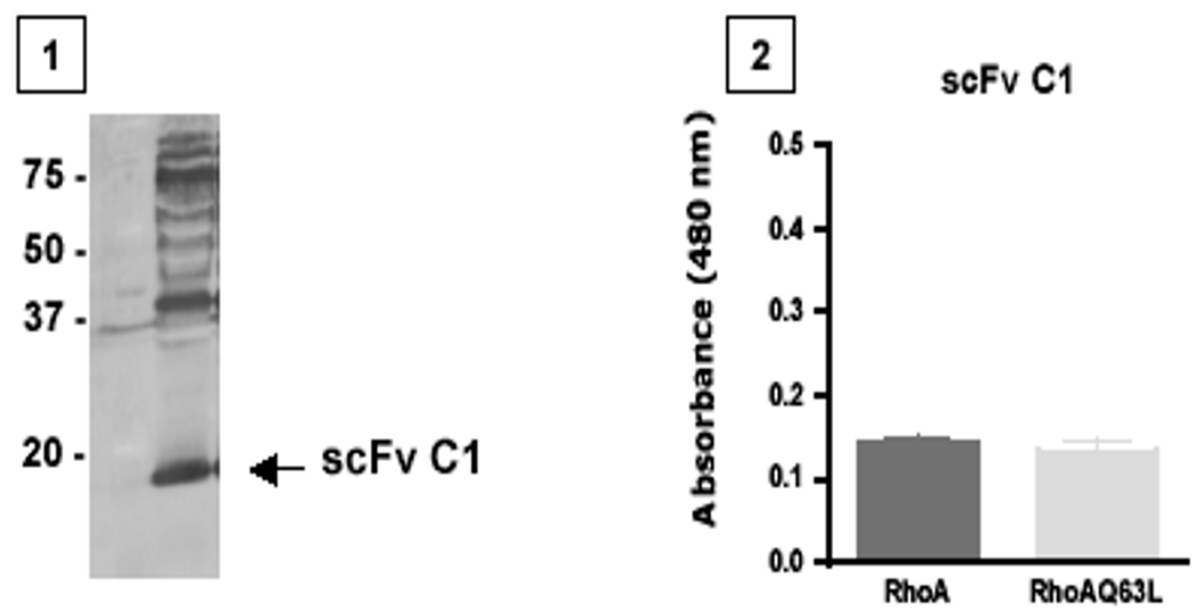

B
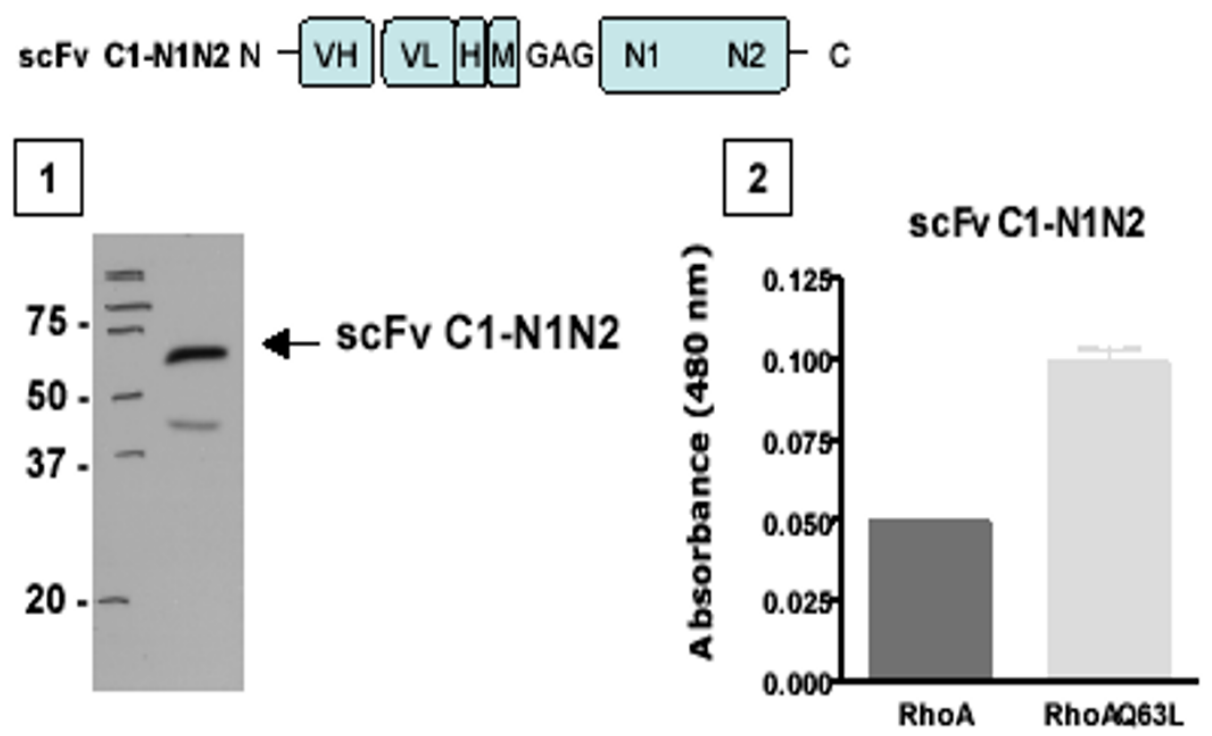

\section{Figure 5}

Binding activity of scFv CI compared to scFv CI-NIN2. (A) scFv CI and (B) scFv CI-NIN2 crude extracts analyzed by (I) Western Blot and (2) ELISA. (I) scFvs were resolved on I2,5\% SDS-PAGE, immunoblotted with c-myc antibody, and visualized by enhanced chemiluminescence as described in Methods. (2) scFvs from crude extract were analysed for binding to GST-RhoA and GST-RhoAQ63L protein immobilized on an ELISA plate. Bound scFvs were detected with horseradish peroxydase-labeled anti-c-myc using TMB as substrate. Results are expressed as absorbance at $480 \mathrm{~nm}$. Graphs are representative of 6 experiments, each performed in duplicate. 
Table I: ELISA competition studies on RhoAQ63L coated plate. ScFvCI-NIN2 (0.4 $\mu \mathrm{M})$ is competed by increasing concentrations of GST-RBD, GDP bound RhoA, GTP bound Cdc 42, GTP bound Rac I. $K_{D}$ of GST-RBD was also determined by surface plasmon resonance on GST-RhoAQ63L.

\begin{tabular}{|c|c|c|c|c|}
\hline & GTP-RhoA & GDP-RhoA & GTP-Cdc42 & GTP-Racl \\
\hline GST-RBD KD $(\mu \mathrm{M})$ & $0.2 \pm 0.2$ & $>50$ & $>50$ & $>50$ \\
\hline ScFvCININ2 KD $(\mu \mathrm{M})$ & $3 \pm 1$ & $>50$ & $>50$ & $>50$ \\
\hline
\end{tabular}

7A). The scFv C1-N1N2 on Ni-NTA beads selectively associated with the GTP-bound form of both RhoA and RhoB, confirming the specificity of this new antibody.

The ability of scFv C1-N1N2 to identify activated Rho was next tested in vivo on activated HeLa cells by immunofluorescence. After serum deprivation $(48 \mathrm{~h})$, HeLa cells were activated 1 hour with EGF (100 ng/ml) and serum (FBS $10 \%$ ) and immunostained with scFvC1-N1N2, irrelevant scFv (anti-thyroglobulin) and anti-c-myc antibodies. We observed that staining with scFv C1-N1N2 (Fig. 7B panel $\mathrm{A}$ andB), but not the irrelevant scFv (Fig. 7B panelF), produced a positive immunofluoresence signal specifically in activated cells (Panel B). To confirm the signal specificity, prior to staining, scFv C1-N1N2 was first incubated with GTP $\gamma$ S- preloaded RhoA to exhauste the selective scFv (negative control) or GDP-preloaded RhoA which would have any effect on scFv activity (positive control). On serum starved cells, little signal was detected with either the scFv C1-N1N2 antibody preincubated with GDPbound RhoA (Fig 7B panel A) or GTP $\gamma$ S-bound RhoA (not shown), although Rho A is detected by a commercial antibody (Fig 7B panelD). Upon activation, a signal was visualized with the scFv C1-N1N2 preincubated with GDPbound RhoA (Fig 7B panel B), showing labelling of the plasma membrane and punctate cytoplasmic structures consistent with previous reports for Rho localization [30]. Similar labelling is obtained with commercial anti-RhoA (Fig 7B panel E). Moreover, this signal was suppressed by preincubation of the scFv C1-N1N2 antibody with GTP $\gamma \mathrm{S}$ preloaded RhoA (Fig 7B panel C). This data strongly suggests that scFv C1-N1N2 is able to recognize endogenous activated and GTP-bound Rho at the cellular level.

\section{Conclusion}

Binding domains of effector proteins have proven to be useful as conformational sensors in analyzing the spatiotemporal activation of GTPases $[31,32]$. In this study, we have shown that a phage display approach identified a specific phage for the GTP-bound form of RhoA, B and C. The expressed and purified scFvC1-N1N2 protein proceeded from this phage is able to recognize the three Rho proteins (A, B and C) loaded with GTP $\gamma \mathrm{S}$ with great specificity, and detect activation of endogenous Rho protein in fixed cells. This finding implicates the potential for $\mathrm{scFv}$
C1-N1N2 as a useful tool to compare the level of activated Rho in cancer tissues versus normal tissues.

\section{Methods}

\section{Construction of PHEN vectors}

The schematic for vector construction is presented in Figure 1. Quick-Change (Stratagene) was used to remove the amber stop codon between scFv and protein III genes in pHEN 2, using the following primers: 5'CTGAATGGGGCCGCAGAGACTG TTGAAAGTTG $3^{\prime}$ and 5'CAACTTTCAACAGTCTCTGCGGCCCCATTCAG 3'. A new EcoRI site was introduced downstream of the pIII N2 region by PCR amplification of this modified plasmid (pHEN C1-pIII) using primers LMB3, 5'-CAGGAAACAGCTATGAC-3', and N2 (EcoR1), 5'CCGGA ATTCGCCGCCGCCAGCATTGAC 3'. The final pHEN C1$\mathrm{N} 1 \mathrm{~N} 2$ vector was constructed by cloning the NcoI/EcoRI digested PCR product into the NcoI and EcoRI digested pHEN C1-pIII plasmid. Constructs were verified by sequencing.

\section{GST-fusion vectors and protein expression}

The Q63L mutation of RhoA, RhoB, and RhoC was generated in the original wild-type cDNA of RhoA, RhoB, RhoC (a gift from Dr. P. Sheffield [33]) cloned into the pGSTparallel2 vector, in frame at the 3' of glutathione-Stransferase, using the QuickChange Site-Directed Mutagenesis kit (Stratagene). The primer for RhoAQ63L 5' GGACACAGCTGGGCTCGAGGATTATGATCG 3', for RhoBQ63L， 5' GGACACGGCGGGCCTCGAGGACTACGACCG 3' and for RhoCQ63L 5' GGACACAGCAGGGCTCGAGGACTATGATCG 3', introduce an internal XhoI restriction site in the pGSTparallel2 DNA sequence. pGEX plasmids expressing GST-Cdc42 and GST-Rac1 were kindly provided by Dr. A. Blangy (CRBM-CNRS, France).

Recombinant GST fusion Rho proteins were expressed and purified in a protease deficient strain (E. coli BL21). Bacteria were grown at $37^{\circ} \mathrm{C}$ in 1 liter of $\mathrm{LB}$ medium containing $100 \mu \mathrm{g} / \mathrm{ml}$ ampicillin until an $\mathrm{OD}_{600}=0.4$ was reached. Protein expression of RhoA, RhoB, RhoC and Rac was induced by overnight incubation (3 hours for Cdc42) with $0.1 \mathrm{mM}$ of isopropyl- $\beta$-D-glactopyranoside (IPTG) at $20^{\circ} \mathrm{C}$, and cells were harvested. Bacteria pellets were frozen at $-20^{\circ} \mathrm{C}$ for $15-20$ minutes, and subsequently resuspended at $4{ }^{\circ} \mathrm{C}$ in $50 \mathrm{mM}$ Tris- $\mathrm{HCl}, \mathrm{pH} 7.5,150 \mathrm{mM} \mathrm{NaCl}$, 
A

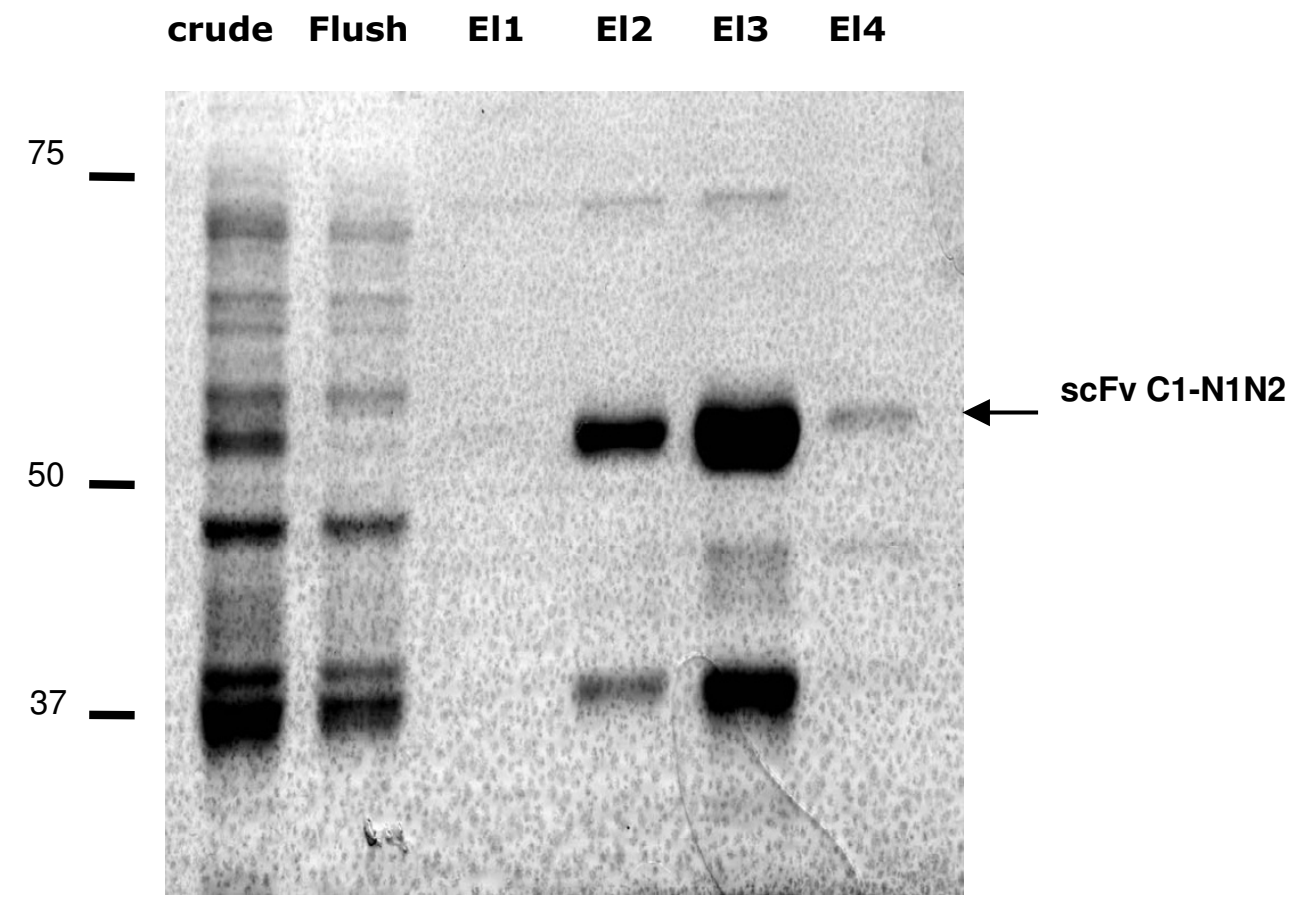

B

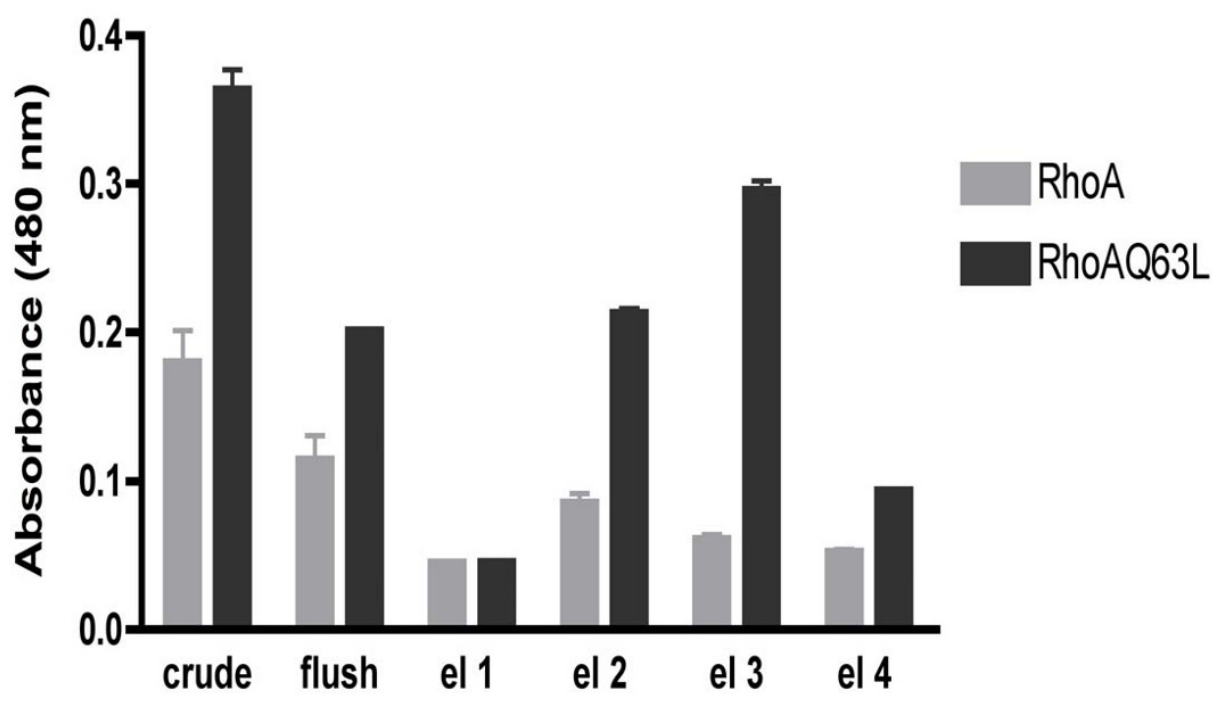

Figure 6

Characterization of enriched scFv CI-NIN2. A: scFv from crude extract was purified on Ni-NTA beads. Fractions (20 $\mu$ l) were resolved on a 12.5\% SDS-PAGE gel, and visualized by Coomassie Blue staining. Crude: total extract; flush: non bound scFv; El (I-4): elution fractions I to 4. B: Each step of purification (I:10 diluted elutions in 3\% milk-PBS) was analyzed for binding to GST-RhoA and GST-RhoAQ63L protein immobilized on an ELISA plate. Bound scFv were detected with horseradish peroxydase-labeled anti-myc using TMB as substrate. Results are expressed as absorbance at $480 \mathrm{~nm}$. Graphs are representative of more than 5 experiments, each performed in duplicate. 
A

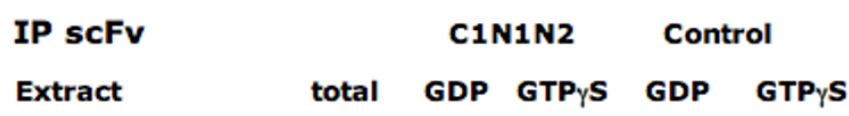

WB: $\alpha$ RhoA

WB: $\alpha$ RhoB

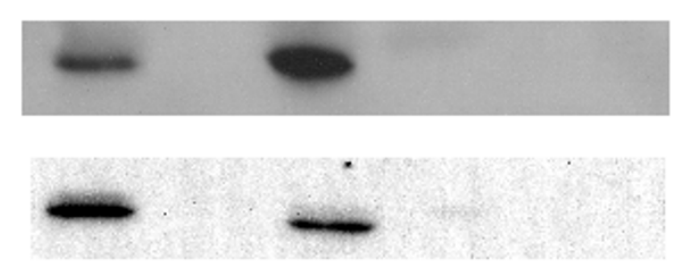

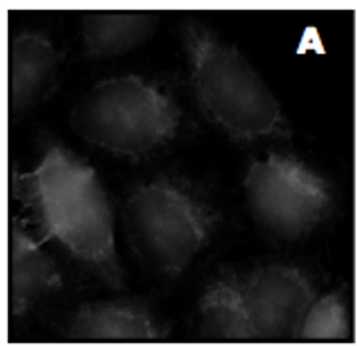
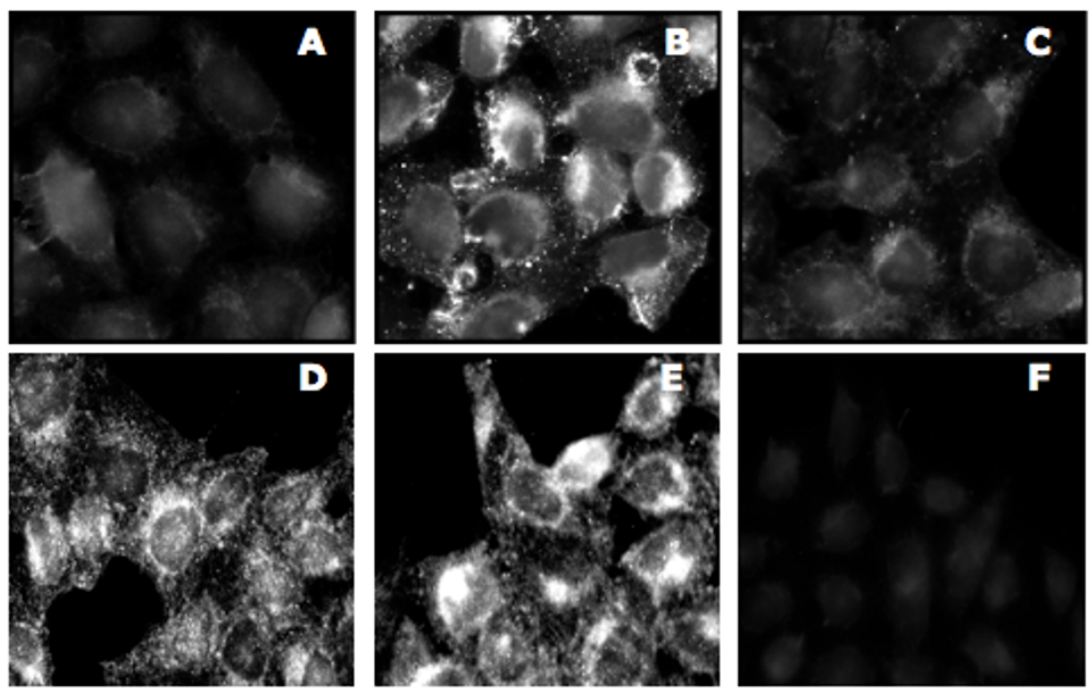

\section{Figure 7}

SCFv CI-NIN2 specifically recognizes GTP-bound Rho in vitro and in vivo. A: scFv CI-NIN2 immunoprecipitation (IP) of GTP-bound RhoA and RhoB. Crude bacterial lysates of recombinant RhoA and RhoB loaded with either GTP or GDP were incubated with scFv CI-NIN2 fixed on Ni-beads. An irrevelant scFv was used as control. Complexes on beads were resolved by SDS-PAGE and immunobloted with anti-RhoA and anti-RhoB. Western Blot is representative of 2 independent experiments. B: Immunofluorescence shows that scFv CI-NIN2 specifically binds to activated HeLa cells. Suspension containing scFv CI-NIN2 was incubated with GDP-loaded RhoA(A and B) or GTP $\gamma$ S-preloaded RhoA beads (C). Twenty-four hours after seeding, HeLa cells were serum-starved for $48 \mathrm{~h}$ and activated with $10 \%$ SVF and EGF (I00 ng/ml) for I hour. Cells were fixed, permabilized and incubated with supernatants from scFv CI-NIN2-Rho incubation and anti-c-myc FITC conjugate secondary antibody. (A) Non-activated HeLa cells incubated with the antibody scFv CI-NIN2 preincubated with GDP-loaded RhoA beads, (B) EGF-activated HeLa cells incubated with the antibody scFv CI-NIN2 preincubated with GDP-loaded RhoA beads (C) EGF-activated HeLa cells incubated with the antibody scFv CI-NIN2 preincubated with GTP $\gamma$ S-loaded RhoA beads. (D) Non-activated Hela cells incubated with the commercial Rhoa antibody, (E) EGF-activated HeLa cells incubated with the commercial RhoA antibody, (F) EGF-activated HeLa cells incubated with irrelevant scFv (anti-tyroglobulin). Pictures are representative of 2 independent experiments. 
$5 \mathrm{mM} \mathrm{MgCl}$ (PBS, $2 \mathrm{mM} \mathrm{MgCl} 2$ for Cdc42) at 1:100 or 1:10 of the original culture volume. Cells were incubated on ice for 30 minutes, sonicated for three $10 \mathrm{sec}$ rounds, and lysate was centrifuged at 7,000 $\times \mathrm{g}$ for 30 minutes. The supernatant was purified by Reacti-Bind ${ }^{\mathrm{TM}}$ glutathione coated strip-well plates (Pierce) or by glutathione sepharose beads (Amersham Pharmacia Biotech) according to the manufacturer's instructions.

\section{Phage libraries and antibody phage display screening}

The Griffin.1 library [24], a human synthetic $\mathrm{V}_{\mathrm{H}}+\mathrm{V}_{\mathrm{L}} \mathrm{scFv}$ phage library in a phagemid vector, and the positive control Escherichia coli TG1 (TG1 containing an anti-tyroglobulin clone) were generously provided by Fiona Sait of The Medical Research Council (Cambridge, England). We followed the protocol provided with the Griffin.1 library [34], as previously described [35]

Briefly, for the first round of selection, phages were incubated with GST-RhoBQ63L-bound glutathione beads (10 $\mu \mathrm{g}$ of Rho protein). For the subsequent three rounds, bound unspecific phages were removed by first incubation with GST-beads, and unbound phages were incubated with GST-RhoBQ63L beads, then eluted and amplified. For the last round, the phages bound on GSTRhoBQ63L beads were competed with soluble wild type recombinant RhoB $(80 \mu \mathrm{g})$.

Reactivity of the identified phages was tested with ELISA and positive clones were sequenced. Phagemids DNAs from individuals colonies were extracted and purified with the Quiafilter plasmid purification kit (Qiagen) and sequenced with the primers LMB3 5'-CAGGAAACAGCTATGAC-3' and pHENseq 5'-CTATGCGGCCCCATTCA-3'. The sequences are compared to the human immunoglobulins sequences and aligned with FRIMGT and CDR-IMGT delimitation [36].

\section{Monoclonal phage ELISA}

Briefly, recombinant GST-Rho proteins were incubated on Reacti-Bind ${ }^{\mathrm{TM}}$ glutathione coated plates for 1 hour at room temperature. One group of 48 colonies and another of 96 colonies from the fifth round of selection were picked manually and tested by ELISA as previously described [37].

\section{Kinetics of Rho GTP loading}

Recombinant GST-RhoA purified on glutathione beads was loaded with $0.1 \mathrm{mM}$ of GDP or GTP $\gamma \mathrm{S}$ in PBS $10 \mathrm{mM}$ EDTA at $37^{\circ} \mathrm{C}$. Loading was repeated several times. A suspension of $\mathrm{C} 1$ phages ( $10^{11}$ clones) in 3\% MPBS, $10 \mathrm{mM}$ $\mathrm{MgCl}_{2}$ was incubated with loaded GST-RhoA beads for 1 hour at room temperature. Beads were washed 3 times with $0.1 \%$ Triton $\times 100$ in PBS. A suspension of peroxidase-labeled anti-M13 antibody (1:5000 dilution in 2\% milk in PBS) was added for 1 hour and the reaction was assayed, using 3,3',5,5' tetramethylbenzidine substrate (Sigma). The reaction was stopped by adding $1 \mathrm{M}$ sulfuric acid, and the absorbance was read at $480 \mathrm{~nm}$.

\section{Production and purification of soluble single-chain Fv antibody}

BL21 E coli non-suppressor strain was transformed with the selected pHEN plasmid, and a selected colony was grown in $100 \mathrm{~mL}$ of 2 xTY medium containing $100 \mu \mathrm{g} / \mathrm{mL}$ ampicillin and $2 \%$ glucose at $37^{\circ} \mathrm{C}$. At proper concentration $\left(\mathrm{OD}_{600}=0.8\right)$, the culture was centrifuged at $3,300 \times$ $\mathrm{g}$ for 10 minutes at $4{ }^{\circ} \mathrm{C}$. Bacteria were resuspended in 2xTY medium containing $100 \mu \mathrm{g} / \mathrm{mL}$ ampicillin and induced with $0.1 \mathrm{mM}$ IPTG overnight at $30^{\circ} \mathrm{C}$ (no more than $16 \mathrm{~h}$ ). Bacteria were harvested, resuspended in spheroplast buffer (200 mM Tris-HCl, pH 8, 0.5 mM EDTA, $0.5 \mathrm{M}$ sucrose) at 1:10 of the culture volume and incubated on ice for 30 minutes. The sample was centrifuged at $3,300 \times \mathrm{g}$ for 10 minutes, and the supernatant containing the $\mathrm{scFv}$ was directly subjected to ELISA analysis.

For scFvs purification, bacteria were harvested, resuspended in $50 \mathrm{mM}$ Tris-HCl, pH 7.5, $150 \mathrm{mM} \mathrm{NaCl}, 2.5$ $\mathrm{mM} \mathrm{MgCl} \mathrm{(1/10} \mathrm{of} \mathrm{the} \mathrm{culture} \mathrm{volume),} \mathrm{incubated} \mathrm{on} \mathrm{ice}$ for 30 minutes and sonicated five rounds for $10 \mathrm{sec}$. The cell lysate was centrifuged at 3,300 $\times \mathrm{g}$ for 10 minutes, and the supernatant was centrifuged at 17,500 $\times \mathrm{g}$ for 1 hour. The supernatant containing the scFvs was adjusted to 300 $\mathrm{mM} \mathrm{NaCl}$ and $1 \mathrm{mM}$ imidazole, and the scFvs were concentrated on $1 \mathrm{ml}$ of $50 \%$ slurry Ni-NTA agarose (Qiagen) at $4{ }^{\circ} \mathrm{C}$ with shaking for at least two hours. After washing with $50 \mathrm{mM}$ Tris- $\mathrm{HCl}, \mathrm{pH} 7.5,300 \mathrm{mM} \mathrm{NaCl}, 10 \mathrm{mM}$ imidazole, bound scFvs were eluted with $50 \mathrm{mM}$ Tris- $\mathrm{HCl}$, pH 7.5, $300 \mathrm{mM} \mathrm{NaCl}, 250 \mathrm{mM}$ imidazole. Samples of all fractions were analysed by SDS-PAGE. ScFvs-containing fractions were pooled and applied to a PD-10 column (G25M Sephadex, GE Healthcare) equilibrated with 50 $\mathrm{mM}$ Tris-HCl, $\mathrm{pH}$ 7.5. Desalted scFvs were analyzed by SDS-PAGE and Coomassie blue staining or Western blotting with anti-c-myc. All fractions containing scFvs were tested by ELISA in conditions detailed above.

\section{Antibodies}

Mouse anti-RhoA (26-C4) and rabbit anti-RhoB (sc-180) antibodies were obtained from Santa Cruz Technology (Santa Cruz, CA); goat anti-GST, mouse anti-M13 (HRP) antibodies were obtained from Amersham Pharmacia Biotech (AB, Les Ulis, France); goat anti-c-myc (HRP) antibodies were obtained from Interchim (Montluçon, France), mouse anti-c-myc-FITC conjugate antibodies were obtained from Zymed (Invitrogen, Cergy Pontoise, France). 


\section{Immunoprecipitation-Western Blot analysis}

Crude protein lysates containing recombinant RhoA and RhoB were loaded with $2 \mathrm{mM}$ GDP or $0.2 \mathrm{mM}$ GTP $\gamma \mathrm{S}$ in PBS, $10 \mathrm{mM}$ EDTA for $30 \mathrm{~min}$ at $30^{\circ} \mathrm{C}$. For immunoprecipitation, beads bound by $\mathrm{scFv} \mathrm{C} 1-\mathrm{N} 1 \mathrm{~N} 2$ or scFv control (anti-tyroglobulin) antibodies were incubated with loaded Rho protein suspension for $45 \mathrm{~min}$ at $4^{\circ} \mathrm{C}$. Beads were washed 3 times with $50 \mathrm{mM}$ Tris- $\mathrm{HCl}, \mathrm{pH}$ 7.5, 150 $\mathrm{mM} \mathrm{NaCl}, 30 \mathrm{mM} \mathrm{MgCl} 2,0.1 \%$ Triton $\times 100$. To remove scFv-protein complexes, beads were denatured in $2 \mathrm{X}$ Laemmli reducing sample buffer, boiled for 5 minutes and separated on $12.5 \%$ SDS-PAGE for Western Blot analysis with anti-RhoA or anti-RhoB antibodies followed by HRPconjugated secondary antibodies. Protein detection was performed using the enhanced and chemiluminescence (ECL) system.

\section{Guanine nucleotide-binding assay}

Recombinant GST-RhoB, GST-Rac1 and GST-Cdc42 were preloaded with [ ${ }^{55}$ S GTP $\gamma S(1000 \mathrm{Ci} / \mathrm{mmol}, 1 \mathrm{mCi} / \mathrm{mL}$, GE Healthcare) or with [ $\left.{ }^{3} \mathrm{H}\right] \mathrm{GDP}(12 \mathrm{Ci} / \mathrm{mmol}, 1 \mathrm{mCi} /$ $\mathrm{mL}, \mathrm{GE}$ Healthcare) at different concentrations ( 0.2 to 20 $10^{-9} \mathrm{M}$ ) in $10 \mathrm{mM}$ EDTA for $30 \mathrm{~min}$ at $37^{\circ} \mathrm{C}$. Specific binding was obtained in the presence of $0.2 \mathrm{mM}$ unlabeled nucleotide. Loaded crude extracts were purified on Reacti-Bind $^{\mathrm{TM}}$ glutathione coated plates for 1 hour at room temperature. Plates were washed twice with PBS $0.05 \%$ Tween-20. $1 \mathrm{~N} \mathrm{NaOH}$ was added to wells to remove bound GST-Rho, and supernatant was collected and diluted in the cocktail used for counting aqueous samples (Ultima Gold, PerkinElmer). Radioactivity bound to GSTRho was determined by scintillation counting.

\section{Immunofluorescence}

Recombinant GST-RhoA fixed on beads (about $600 \mu \mathrm{g}$ of protein) was loaded with $100 \mu \mathrm{M}$ GTP $\gamma$ S or GDP in 10 $\mathrm{mM}$ EDTA for 1 hour at $37^{\circ} \mathrm{C}$. Purified scFvs $(0.5 \mathrm{mg} / \mathrm{ml})$ was incubated with beads for 1 hour at room temperature, and incubation was repeated twice. HeLa cells (ATCC, CCL-2) grown on coverslips were stimulated with $100 \mathrm{ng} /$ ml of EGF (Sigma) and 10\% FBS for one hour, then fixed with paraformaldehyde (Cytofix) and permeabilized with Cytoperm (BD Biosciences). Supernatant alone or containing scFvs after incubation with loaded beads was incubated with cells for 90 minutes. Coverslips were rinsed once in PBS, $5 \mathrm{mM} \mathrm{MgCl}$ and incubated with $2 \mu \mathrm{g} / \mathrm{ml}$ of anti-c-myc FITC conjugate secondary antibody (9E10, Zymed). Staining was visualized using a Nikon eclipse 90i microscope equipped with fluorescence FITC filters (Semrock) and a CoolsnapHQ ${ }^{2}$ camera (Ropper). Images were acquired using NIS-Element Ar.

\section{Abbreviations}

scFv: single chain Fragment variable; GST: glutathione sulfonyl transferase; MPBS:milk phosphate buffer saline;
EGF:epidermal growth factor; FBS: foetal bovine serum; FITC: fluorescein isothiocyanate; RBD: Rho binding domain of Rhotekin

\section{Authors' contributions}

MG constructed the plasmids, generated recombinant proteins for analysis, performed the ELISA, pull down and immunofluorescence studies, and participated in drafting the manuscript. PC generated the E. coli phage display and contributed to the production and the biochemical characterization of scFvC1. ILM contributed to the plasmid and GST-proteins constructions, as well as drafted the manuscript. CMG assisted with the radionucleotide assay. GF designed and coordinated the study, helped to draft the manuscript, and organized funding. JCF drafted the manuscript and participated in the design and coordination of the study. All authors read and approved the final manuscript.

\section{Acknowledgements}

We would like to thank Fiona Sait for kindly providing the Griffin I. library, and Anne Blangy for providing plasmids containing coding DNA of GSTCdc42 and GST-Racl. We also gratefully acknowledge Jean-Pierre Estève and Frederic Lopez for performing the SPR experiments, and Anne Pradines and Caroline Delmas for helpful assistance in cell imaging. We gratefully acknowledge Franck Perez for his helpful advice. MG is a recipient fellowship from the Association de la Recherche contre le Cancer (ARC).

\section{References}

I. Wennerberg K, Der Cl: Rho-family GTPases: it's not only Rac and Rho (and I like it). J Cell Sci 2004, I I 7(Pt 8): I30I-I3 I 2.

2. Etienne-Manneville $S$, Hall A: Rho GTPases in cell biology. Nature 2002, 420(6916):629-635.

3. Sahai E, Marshall CJ: RHO-GTPases and cancer. Nat Rev Cancer 2002, 2(2): 133-142.

4. Worthylake RA, Lemoine S, Watson JM, Burridge K: RhoA is required for monocyte tail retraction during transendothelial migration. J Cell Biol 200I, I 54(I): I47-160.

5. Engers R, Springer E, Michiels F, Collard JG, Gabbert HE: Rac affects invasion of human renal cell carcinomas by up-regulating tissue inhibitor of metalloproteinases (TIMP)-I and TIMP-2 expression. J Biol Chem 200I, 276(45):4I889-4I897.

6. Khosravi-Far R, Solski PA, Clark GJ, Kinch MS, Der CJ: Activation of Racl, RhoA, and mitogen-activated protein kinases is required for Ras transformation. Mol Cell Biol 1995, I 5 (I I):6443-6453.

7. Qiu RG, Chen J, Kirn D, McCormick F, Symons M: An essential role for Rac in Ras transformation. Nature 1995, 374(652 I):457-459.

8. Qiu RG, Chen J, McCormick F, Symons M: A role for Rho in Ras transformation. Proc Natl Acad Sci U S A 1995, 92(25): I |78I-II 785.

9. Prendergast GC, Khosravi-Far R, Solski PA, Kurzawa H, Lebowitz PF, Der CJ: Critical role of Rho in cell transformation by oncogenic Ras. Oncogene 1995, I O(I 2):2289-2296.

10. Welsh CF, Assoian RK: A growing role for Rho family GTPases as intermediaries in growth factor- and adhesion-dependent cell cycle progression. Biochim Biophys Acta 2000, I 47 I (I):M2I-9.

II. Ellis $\mathrm{S}$, Mellor $\mathrm{H}$ : Regulation of endocytic traffic by rho family GTPases. Trends Cell Biol 2000, 10(3):85-88.

12. Qualmann B, Mellor H: Regulation of endocytic traffic by Rho GTPases. Biochem J 2003, 37 I(Pt 2):233-24I.

13. Gampel A, Parker PJ, Mellor H: Regulation of epidermal growth factor receptor traffic by the small GTPase rhoB. Curr Biol 1999, 9 ( I 7):955-958. 
14. Lacal JC: Regulation of proliferation and apoptosis by Ras and Rho GTPases through specific phospholipid-dependent signaling. FEBS Lett 1997, 4 I 0(I):73-77.

I5. Joneson T, Bar-Sagi D: Suppression of Ras-induced apoptosis by the Rac GTPase. Mol Cell Biol 1999, I9(9):5892-590I.

16. Gomez del Pulgar T, Benitah SA, Valeron PF, Espina C, Lacal JC: Rho GTPase expression in tumourigenesis: evidence for a significant link. Bioessays 2005, 27(6):602-6I3.

17. Kamai T, Arai K, Tsujii T, Honda M, Yoshida K: Overexpression of RhoA mRNA is associated with advanced stage in testicular germ cell tumour. BJU Int 200I, 87(3):227-23I.

18. Suwa $H$, Ohshio $G$, Imamura $T$, Watanabe $G$, Arii S, Imamura $M$ Narumiya S, Hiai $H$, Fukumoto M: Overexpression of the rhoC gene correlates with progression of ductal adenocarcinoma of the pancreas. $\mathrm{Br} /$ Cancer I998, 77(I): |47-|52.

19. Mazieres J, Antonia T, Daste G, Muro-Cacho C, Berchery D, Tillement V, Pradines A, Sebti S, Favre G: Loss of RhoB expression in human lung cancer progression. Clin Cancer Res 2004 I 0(8):2742-2750.

20. Aznar S, Fernandez-Valeron P, Espina C, Lacal JC: Rho GTPases: potential candidates for anticancer therapy. Cancer Lett 2004 206(2): |81-19|

21. Mira JP, Benard V, Groffen J, Sanders LC, Knaus UG: Endogenous, hyperactive Rac 3 controls proliferation of breast cancer cells by a p2 I-activated kinase-dependent pathway. Proc Natl Acad Sci U S A 2000, 97(I): |85-189.

22. Nizak C, Monier S, del Nery E, Moutel S, Goud B, Perez F: Recombinant antibodies to the small GTPase Rab6 as conformation sensors. Science 2003, 300(562I):984-987.

23. Longenecker K, Read P, Lin SK, Somlyo AP, Nakamoto RK, Derewenda ZS: Structure of a constitutively activated RhoA mutant (Q63L) at I.55 A resolution. Acta Crystallogr D Biol Crystallogr 2003, 59(Pt 5):876-880.

24. Griffiths $A D$, Williams SC, Hartley $O$, Tomlinson IM, Waterhouse $P$, Crosby WL, Kontermann RE, Jones PT, Low NM, Allison TJ, et al.: Isolation of high affinity human antibodies directly from large synthetic repertoires. Embo J 1994, I 3( I 4):3245-3260.

25. Self AJ, Hall A: Measurement of intrinsic nucleotide exchange and GTP hydrolysis rates. Methods Enzymol 1995, 256:67-76.

26. Jensen KB, Larsen M, Pedersen JS, Christensen PA, Alvarez-Vallina L, Goletz S, Clark BF, Kristensen P: Functional improvement of antibody fragments using a novel phage coat protein III fusion system. Biochem Biophys Res Commun 2002, 298(4):566-573.

27. Bousquet C, Guillermet-Guibert J, Saint-Laurent N, Archer-Lahlou E, Lopez F, Fanjul M, Ferrand A, Fourmy D, Pichereaux C, Monsarrat B, Pradayrol L, Esteve JP, Susini C: Direct binding of p85 to sst2 somatostatin receptor reveals a novel mechanism for inhibiting PI3K pathway. Embo / 2006, 25( I 7):3943-3954.

28. Horn IR, Wittinghofer A, de Bruine AP, Hoogenboom HR: Selection of phage-displayed fab antibodies on the active conformation of ras yields a high affinity conformation-specific antibody preventing the binding of c-Raf kinase to Ras. FEBS Lett 1999, 463( I-2): I I5-120.

29. Tanaka T, Rabbitts TH: Intrabodies based on intracellular capture frameworks that bind the RAS protein with high affinity and impair oncogenic transformation. Embo I 2003 22(5): $1025-1035$.

30. Michaelson D, Silletti J, Murphy G, D'Eustachio P, Rush M, Philips MR: Differential localization of Rho GTPases in live cells: regulation by hypervariable regions and RhoGDI binding. J Cell Biol 200I, I52(I): III-I26.

31. Pertz O, Hahn KM: Designing biosensors for Rho family proteins--deciphering the dynamics of Rho family GTPase activation in living cells. / Cell Sci 2004, I I 7(Pt 8): | 3 | 3-13 I8.

32. Nakamura T, Kurokawa K, Kiyokawa E, Matsuda M: Analysis of the spatiotemporal activation of rho GTPases using Raichu probes. Methods Enzymol 2006, 406:315-332.

33. Sheffield PJ, Derewenda U, Taylor J, Parsons TJ, Derewenda ZS: Expression, purification and crystallization of a $\mathrm{BH}$ domain from the GTPase regulatory protein associated with focal adhesion kinase. Acta Crystallogr D Biol Crystallogr 1999, 55(Pt I):356-359.

34. MRC Centre for Protein Engineering [http://www.mrccpe.cam.ac.uk/]
35. Nizak C, Moutel S, Goud B, Perez F: Selection and application of recombinant antibodies as sensors of rab protein conformation. Methods Enzymol 2005, 403:135-153.

36. IMGT $®$ IMGT: IMGT $®$, the international ImMunoGeneTics information system $\AA$. [http://imgt.cines.fr].

37. Martinez-Torrecuadrada J, Cifuentes G, Lopez-Serra P, Saenz P, Martinez A, Casal Jl: Targeting the extracellular domain of fibroblast growth factor receptor 3 with human single-chain Fv antibodies inhibits bladder carcinoma cell line proliferation. Clin Cancer Res 2005, I I ( I 7):6280-6290.
Publish with Biomed Central and every scientist can read your work free of charge

"BioMed Central will be the most significant development for disseminating the results of biomedical research in our lifetime. "

Sir Paul Nurse, Cancer Research UK

Your research papers will be:

- available free of charge to the entire biomedical community

- peer reviewed and published immediately upon acceptance

- cited in PubMed and archived on PubMed Central

- yours - you keep the copyright
BioMedcentral 